Original paper

\title{
Incorporating Public Participation into Landslide Risk Information and Response: Disaster Response Switch in the Taisho District of Shimanto- cho, Kochi, Japan
}

\section{Kensuke Takenouchi ${ }^{1}$}

Received: 28/02/2020 / Accepted: 13/08/2020 / Published online: 24/09/2020

\begin{abstract}
A disaster response switch is a tool for incorporating public participation into disaster risk information and response and is considered by communities in determining the timing of disaster response actions through a combination of local information in the community and public information from local government and professional organizations. In this study, a trial for a disaster response switch for landslide risk was conducted in the Taisho District, Shimantocho, Kochi, Japan. The study verified a method for implementing the switch and the effects of this public participation. The results showed that the communities largely considered switches based mostly on local information. In addition, they improved their understanding of the relationships between subjective local information and objective public disaster risk information through bosai (disaster prevention) recording, where communities take pictures of places around the disaster response switches as community records. This trial showed the importance of considering communities' participation when they evacuate. The public participation of the disaster response switch moved the focus of risk information from the contents or accuracy of the information to the social system of evacuation action in the community, based on the acceptance of uncertainty in the information.
\end{abstract}

Keywords: Public participation, Disaster response switch, Disaster information, Community disaster prevention, Landslide

\footnotetext{
${ }^{1}$ Faculty of Engineering and Design, Kagawa University,

Disaster Prevention Research Institute, Kyoto University (Former affiliation)
} 


\section{INTRODUCTION}

Recently, various extreme meteorological phenomena have increasingly occurred worldwide (Hoeppe 2015). This situation affects Japan, where torrential rainfall events exceeding estimated scales have caused damage to cities every year (Japan Meteorological Agency 2020). To address this, governments have adopted policies based primarily on disaster information (meteorological warnings, evacuation information, etc.) to improve pre-evacuation behavior before meteorological disasters occur. For example, they have introduced emergency warning systems to announce the highest-risk situations when meteorological warnings are issued. Such systems categorize disaster information into five levels to communicate the risk level clearly. However, the low evacuation rate during meteorological disasters in Japan is a major issue (Okamoto et al. 2012); although this situation has yet to be fully resolved, disaster information has improved.

Takenouchi et al. (2020) proposed the "Disaster Response Switch (DRSwitch)" to create an evacuation system based on passive public disaster information from outside sourcesmeteorological warnings or evacuation information — and local information produced through community participation - precursory phenomena or past experiences in a community. The DRSwitch is based on community participation related to disaster risk information and response. Communities make the disaster response rules within themselves, switching their behavior and consciousness from normal mode to disaster mode. They make DRSwitches through the combination of local information and public disaster information. The DRSwitch helps establish judgment standards for disaster responses in a community and clarifies the relationship between local and public disaster risk information so that various disaster information can be used in a disaster effectively.

If public disaster risk information is sufficient, communities can easily establish the proper DRSwitch. For example, the water levels of some rivers can be used to judge flood risk visually. Landslides, however, are both highly local and unpredictable, making them comparatively more difficult to predict. These characteristics make it difficult for communities to judge disaster responses against landslides based on disaster risk information. Furthermore, evacuation becomes complicated during landslides, making pre-evacuation by communities extremely important. However, Japan has faced multiple challenges to smooth evacuation. Three-quarters of the country is mountainous, and there are over 660,000 risk-prone locations, such as those designated as landslide disaster warning areas or landslide disaster special warning areas (Ministry of Land, Infrastructure, Transport and Tourism 2019). The landslide risk of each city and town should be assessed. Most deaths and missing persons due to meteorological disasters are due to landslides. A survey by Ushiyama (2015) showed that from 2004 to 2013 , landslides accounted for $43.5 \%$ of fatalities during meteorological disasters.

Takenouchi et al. (2020) considered DRSwitches for flood disasters, whose risk can be easily judged from the water level, and classified the DRSwitches by the sufficiency of relevant public disaster risk information. This study refers to their method and considers a method for constructing DRSwitches for landslides together with various members in a research field. Landslide risk cannot be judged easily because of high locality and uncertain occurence; 
therefore, communities take pictures near spots flagged by DRSwitches to grasp the relationships between local situations and public disaster risk information (bosai recording). This study does not focus on the contents of the DRSwitches but on the cooperation between local and public disaster risk information. Based on the results, this study verifies action research of public participation that incorporates local and public disaster risk information and discusses the importance of such cooperation through DRSwitches.

\section{RELATED STUDIES}

\subsection{Disaster information on landslides and evacuation}

Recently, various methods to evaluate landslide risk have been developed, although the nature of disaster information for landslides varies by country and region. In the case of Japan, there are four basic pieces of disaster risk information for landslides: heavy rainfall advisories, warnings, emergency warnings, and sediment disaster alerts. This information is based not on the preceding amount of rainfall but soil water content calculated by a physical model of groundwater movement (Okada et al. 2001). For analysis of landslide risk, most countries other than Japan use methods based on the laws of natural science, such as rainfall, or results from physical models.

Segoni et al. (2018) reviewed 107 recent studies on rainfall thresholds for landslide occurrence (115 thresholds). The literature collected on rainfall thresholds fell into four categories: publication details, geographical distribution and uses, dataset features, and threshold definition. These results showed that rain gauges made up $79.5 \%$ of the rainfall source. Further, $48.6 \%$ listed intensity duration as a threshold parameter, and most thresholds were based on basic observation on rainfall. The studies had some issues concerning validation. For example, about $40.0 \%$ lacked any analysis of predictive capability. Nevertheless, many discussions of the rainfall threshold for landslide occurrence show that the general risk information on landslides is defined by the laws of natural science; their accuracies have improved in recent years.

When checking actual landslide evacuation cases in communities, there are cases of safe evacuations based on factors other than those based on natural science. Chiba et al. (2008) reported a case of huge rainfall in July 2006. This disaster caused landslides in Okaya and Suwa cities in Nagano prefecture. However, there were differences in the cities' evacuation. The Suwa community noticed precursory phenomena and took pre-evacuation measures. This was derived from the usual cooperation between the community and the local government. The local government rapidly issued evacuation information based on local information from a leader's inspection. Irasawa and Endo (2010) conducted a questionnaire survey for communities in Kamaishi City, Iwate Prefecture, which were damaged by landslides during Typhoon Chataan in 2002. The results showed that $40 \%$ of the people in the communities who noticed some precursory phenomena tended to consider whether to evacuate. Huang et al. (2015) reported a case of stakeholders' judgment based on such precursory land changes as a 
successful case of emergency landslide response. Members of the public reported timely clues in slope deformation, and landslide specialists and governmental officials made prompt collaborative decisions that contributed to a successful emergency evacuation. Chen and Fujita (2013) noted that "Inhabitants take evacuation actions based on environmental conditions or the aforementioned government-issued warning information, including evacuation preparedness, voluntary evacuation, and mandatory evacuation." However, the results of an analytic hierarchy process (AHP) method from some questionnaires on decision-making factors for government officers and people in Taiwan showed most people were more influenced by "circumstances" than if they "receive alerts." In addition to such situations, some cases involved evacuations based on warning information, such as evacuation orders.

Conversely, the number of pre-evacuation cases for landslides is small. Surveys in 206 locations where human or residential damage occurred due to huge rainfall in July 2006 and during the 13th typhoon of the same year showed pre-evacuations by community judgment were found in only 5\% of cases (10 locations) (Japan Erosion and Sediment Control Department 2009).

From Kikui and Sano's (2008) questionnaire survey to communities affected by the Niigata heavy rainfall in 2004, most communities evacuated just when they noticed some phenomena on landslides, and some communities only evacuated after landslides happened. Similarly, Takahashi et al. (2005) surveyed the details of communities' actions in Minamata city, Kumamoto prefecture, which was affected by a debris flow in July 2003. The communities took actions to prepare for the disaster based on the realization that "This situation isn't usual"; however, they did not understand the precursory phenomena that might have given them an early warning. Consequently, most communities evacuated after the debris flow. There are cases of safe pre-evacuation in some areas, but other communities failed to evacuate safely.

\subsection{Public participation in disaster information}

Experts on landslides have advanced landslide disaster risk information. In addition, the Sendai Framework for Disaster Risk Reduction 2015-2030 (United Nations 2015) noted the importance of local communities' participation in disaster mitigation and the need to consider each community's characteristics. Researchers discussed some public participation in disaster risk information, but these cases have used various methods as below cases show.

Chen et al. (2014) reported on non-structural preventive strategies developed by the government in Taiwan. One strategy is "debris flow professional volunteers." Residents in communities near debris flow torrents have been recruited since 2005 by the Soil and Water Conservation Bureau as debris flow professional volunteers to assist with real-time rainfall monitoring, disaster notification, and local evacuation tasks. During routine days, debris flow professional volunteers inform communities about the local environment, areas vulnerable to debris flows, and relevant disaster prevention information. When typhoons or torrential rains occur, these professional volunteers cooperate for monitoring the local real-time rainfall using simple rain gauges and report their readings using available communication equipment. In 
addition to providing rainfall data in areas lacking formal rainfall stations, they assist with disaster notification and advise their communities to evacuate. Chen and Huang (2010) reported actual cases where this system worked efficiently. This system in Taiwan characteristically creates cooperation between communities and government officers and encourages public participation in disaster risk information through rain gauges. Such a community-based rain gauge system has spread in various countries (Oi et al. 2016; Smith et al. 2017; Gautam et al. 2013; Catherine et al. 2012).

In Japan, what some communities tried to share was not rain gauge information but reference information around their districts. In Minamiawaji, volunteers from a fire department help the local government issue evacuation information. Volunteer members of the fire department check local situations and inform the local government officers. Subsequently, the local government considers the issuance of evacuation information. Such cooperation conventionally occurs in various districts, but in this case, the local government constructively promotes and controls this collaboration (Japan Fire and Disaster Management 2016). A similar practice of community monitoring occurred in Sayo town, Hyogo prefecture, where major human losses occurred when they evacuated in a torrential rainfall by Typhoon Etau in 2009 (Tamura 2016).

Weathernews Inc. (2016), as a local government service, serves as a community participatory "Disaster Reduction Project." Weathernews Inc. has operated a "Weather Reporter" service for consumers. The Weather Reporter service is used by approximately 130,000 users per day. A user registers weather photos and messages through a smartphone application, which explains each local situation. The registered information is shown on a map, and all users can access each other's information and gain more detailed information about situations in which general weather information cannot be expressed. Weathernews Inc. applied the features of the "Weather Reporter" to the "Disaster reduction project." Local governments use this service to share the detailed conditions of each district. Communities register various information for each district, such as river water level, local inundation, traffic conditions, and lifeline availability, and they understand situations and act in reference to others' information. Based on community information, local governments grasp local situations on maps and consider appropriate responses.

The United States Geological Survey (USGS) started “Did You Feel It?” (DYFI)—a system to collect information from people who experienced an earthquake - in 1999. This system collects data through an internet website regarding what people experienced, the extent of any damage, and information on the location of responders, such as postal codes. The collected data can be used to make automatic maps, such as "Community Internet Intensity Maps" (CIIMs), which contribute to the quick assessment and analysis of earthquakes. DYFI data were used by Atkinson and Wald (2007) to calculate the modified Mercalli intensity (MMI) from DYFI data and then compared the two to observed ground motions. The results indicated the usefulness of the DYFI data because it showed differences in earthquakes' intensity with distance of earthquakes between California and the central and eastern United States. Cremen et al. (2017) pointed out the issue that DYFI tends to evaluate stronger intensities compared to actual observations. However, Wald et al. (2011) clarified the advantage of widespread use of 
the DYFI system that has been used worldwide, including in the USA $(1,603,100$ of individual entries in the USA and 140,623 outside of the USA on July 2011). With summaries of response situations of entries and the accuracies, Wald et al. (2011) said that a major advantage of the DYFI system was that its contributors do not need to be trained for the task and its participants are not "citizen scientists"; rather, DYFI is "citizen-based" science.

Similar to the public participation of mass users, in recent years, we have also seen some efforts to utilize Big Data to clarify disaster sites and other information. In this manner, we note the development of many systems that utilize user-collected data. Aulov and Halem (2012) analyzed the Deepwater Horizon oil spill disaster using social media data as a human sensor network. In this analysis, the researchers gathered social media data that mention oil sightings from the Flickr social media community, geolocated them, and used them as boundary forcings in the General NOAA Oil Modeling Environment (GNOME) software for oil spill predictions. Thus, they showed how social media data could be incorporated into the GNOME model to obtain improved estimates of the model parameters. In this case, public participation through social media data was used to improve information quality through predictive modeling. For the useful application of these users' information, technological methods and improvements in certainties have been developed rapidly. For example, Asakura et al. (2016) proposed a new task for classifying a flood disaster with information from social media, in addition to predicting the geolocation of events from the user-generated text, reported the annotation of the flood disaster corpus, and developed a classifier to demonstrate the use of this corpus for disaster analysis. Further, Ma et al. (2014) evaluated the relationship between mass tweets and disasters in the spatial heterogeneity of the data.

Public participation in disaster risk information is also discussed in early warning systems (EWS). Baudoin et al. (2016) explored various pathways to involve local communities in EWS from top-down to more participatory approaches based on a literature review. Three case studies in Kenya, Hawaii, and Sri Lanka were outlined at various participatory levels. Each of their participatory cases have different characteristic as community-centric approaches and depend on conditions such as location, access to risk information, use of communication devices, and level of response capability. Based on their findings, Baudoin et al. (2016) suggested a need to review the way EWS are designed and applied, promoting a shift from the traditional expert-driven approach to one that is embedded at the grassroots level and driven by vulnerable communities. Through educational projects in São Luiz and Cunha in Brazil, Marchezini et al. (2017) suggested a valuable means of drawing on guiding principles of education to work out a participatory EWS in four interrelated areas (risk knowledge, monitoring, communication of warnings, and response capability). They showed that networking for the protection of local communities is a suitable way to address the aims of a "first mile" approach as a participatory EWS. The project was able to interconnect several spheres through a dialogue-oriented learning process that included the municipal civil defense systems, high school students and teachers, local communities, universities, and researchers from the federal government).

As the above cases show, we need to promote the development of methods for public participation in disaster risk information in addition to the extensive development of 
forecasting and observation technologies. The DRSwitch can apply the concept of public participation to disaster risk information. Therefore, it can be regarded as a bottom-up approach for communities. However, the DRSwitch is a collaborative approach that creates cooperation between bottom-up local information and top-down public disaster risk information. It changes the social system on disaster risk information. A DRSwitch's objective is that communities, specialists, and government officials participate in consideration of communities' disaster responses together, sharing not only public disaster risk information but also local knowledge and observations.

\section{METHODS}

This study verifies a method to construct DRSwitches for landslides (here and below, "landslide" refers to various types of events, such as the failure of steep slopes, debris flows, and other landslides) and bosai recording to understand the relationships between the constructed DRSwitches and public disaster risk information. Through this trial, the researcher checks how communities consider participation in disaster risk information on landslides and what roles the DRSwitch's approach can take in the cooperation of stakeholders. The results should expand and deepen our understanding of what types of DRSwitches are appropriate for advancing communities' evacuation.

The Taisho District in Shimanto-cho, Kochi, Japan, was set as the research field (516 households, 1,160 persons according to the 2015 National Population Census), where a practical trial of a DRSwitch for landslides was conducted. As Figure 1 shows, the Taisho District is located in a mountainous area surrounded by $300-400 \mathrm{~m}$ high mountains. Most residential areas are designated as landslide disaster warning areas or landslide disaster special warning areas, where have some landslide risks. Mountainous areas in Japan are formed by orogeny and river erosion; the Taisho District is representative of areas at risk of landslides. The Taisho District is divided into three community areas: north, central, and south.

The trial was conducted cooperatively between representatives of voluntary disaster prevention organizations, the general communities, the local government, and the researcher. Workshops were conducted with the cooperation of voluntary disaster prevention organizations and local government. The period of the trial was from March 2019 to February 2020, but the communities considered DRSwitches and tried using them in this period and are expected to continue using them. 


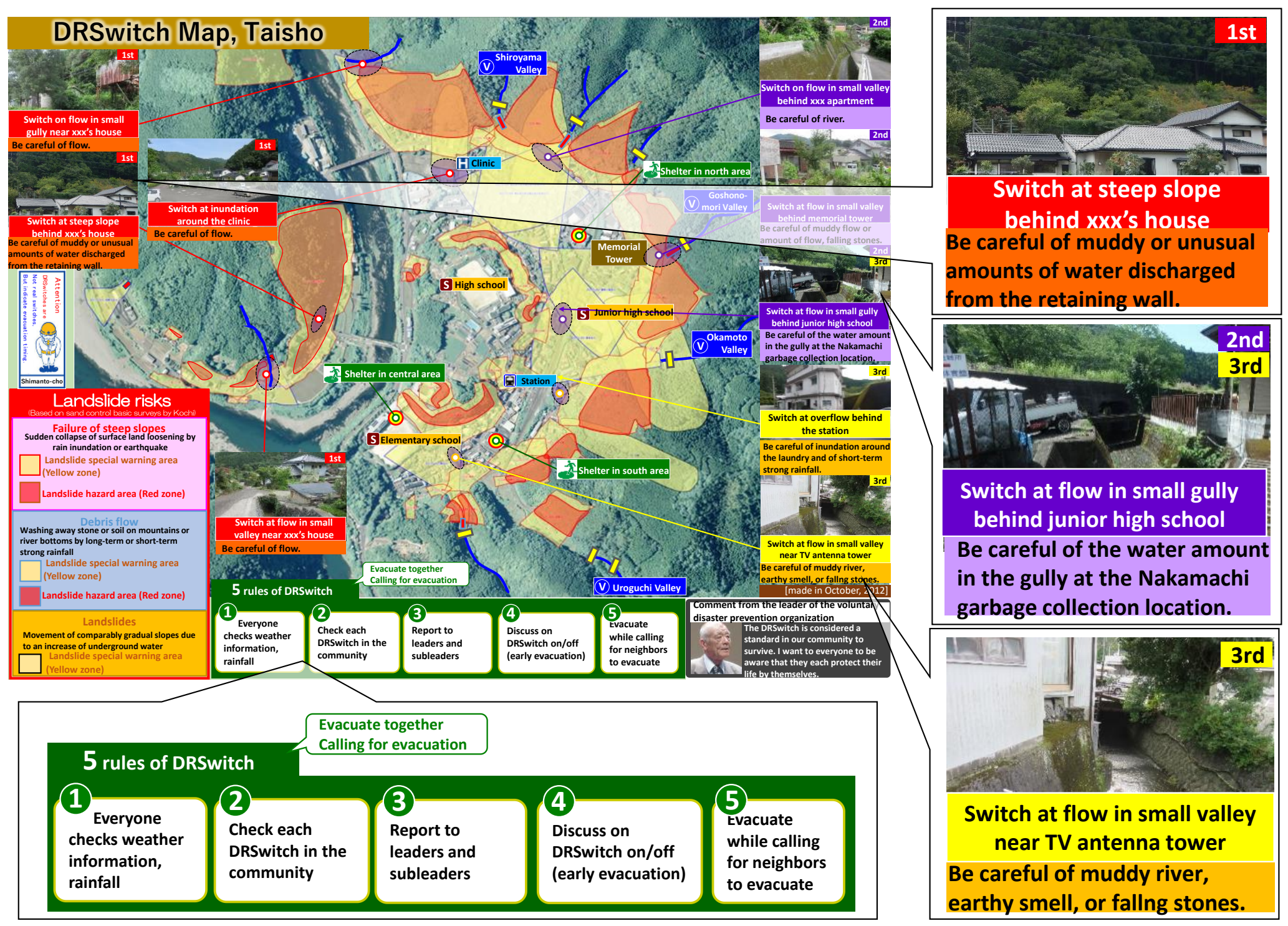

Figure 1. Research Field (Taisho) and examples of constructed DRSwitches (WS1, WS2) 
As shown by Takenouchi et al. (2020), a DRSwitch needs at least three items: i) content, ii) relevant disaster risk information, and iii) disaster responses appropriate to the DRSwitch. Therefore, Takenouchi et al. (2020) held five workshops to construct DRSwitches on flood risk, comprising WS1 (understanding DRSwitches), WS2 (selection of DRSwitches), WS3 (checking disaster risk information), WS4 (consideration of disaster responses), and WS5 (summary), with "WS" signifying "workshop."

Appropriate methods to construct DRSwitches vary depending on the disaster risks, social situations, and activities in communities. Stakeholders discussed procedures for constructing DRSwitches. Communities consider disaster prevention lecture meetings and evacuation drills as important events, which are conducted annually with comparatively more community participation. Therefore, we decided that these events should be used for the trial. Public disaster risk information is lacking and unclear regarding landslide risk. Therefore, we decided to use local disaster risk information first and consider the use of related public disaster risk information gradually. Finally, we constructed a DRSwitch Consideration Committee in Taisho, which consisted of the three communities, two members of the volunteer fire department of each area, and representatives from a local kindergarten, elementary school, junior high school, and high school. The total number of committee members was 48: 23 in the northern area, 13 in the central area, and 12 in the southern area. A DRSwitch can have various types of evacuation warnings, such as staying home or returning home; however, we decided to make DRSwitches for the evacuation of the general residents of the communities because most districts have landslide risks that may necessitate evacuation.

There were six workshops, including two events attended by the general residents of the communities (WS1, WS4): WS1, consideration of content by general residents of the communities; WS2, selection of DRSwitches; WS3, discussion of DRSwitch evacuation drills to check disaster responses; WS4, DRSwitch evacuation drill by general residents of the communities; WS5, connection between local and public disaster risk information; and WS6, summary.

A summary of each workshop appears below. Figure 2 shows scenes from the workshops.

WS1: Consideration of content by general residents of the communities (9:00-11:45 March 17, 2019; about 100 persons)

Landslide risk depends on location, and individual can focus on different areas to apply caution; therefore, we used a disaster prevention lecture meeting to gather various opinions. First, the local government showed the trial in the Taisho District, and the author explained DRSwitches through actual cases. The participants discussed candidate DRSwitches using a district hazard map. The participants were separated into nine groups, and they checked both the hazard map and the various candidate DRSwitches to express representative landslide risks based on their past experiences and observations from their everyday lives. 
WS2: Selection of DRSwitches (18:00-19:45 May 30, 2019; 33 persons)

As mentioned, this trial focused on local disaster risk information as a reference for DRSwitches because of insufficient information expressing local landslide risk. The committee summarized the candidates' discussion from WS1 to risk information based on characteristics such as landslide risk around the area or inundation risk in a gully. Next, they evaluated each risk and discussed the proper situation for pre-evacuation.

WS3: Discussion of DRSwitch evacuation drills to check disaster responses (18:00-20:00 July 30, 2019; 25 persons)

The committee discussed their responses when a local situation might reflect a DRSwitch. However, they also performed the DRSwitch evacuation drill for the first time so that the representatives of the committee and local government could set the flow of the evacuation drill before WS4, as Figure 3 shows. The members of the committee then finalized the content of WS4.

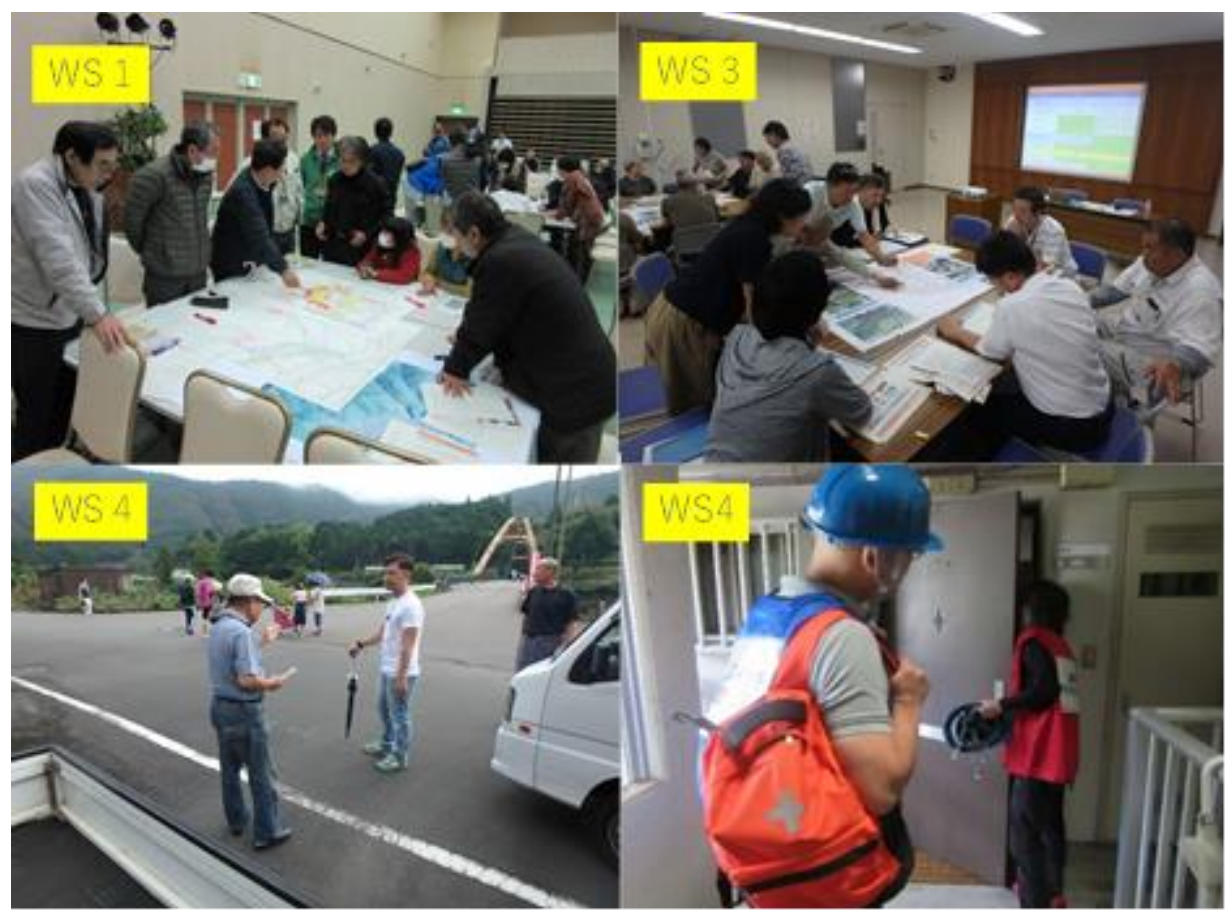

Figure 2. Workshops in the Taisho District 


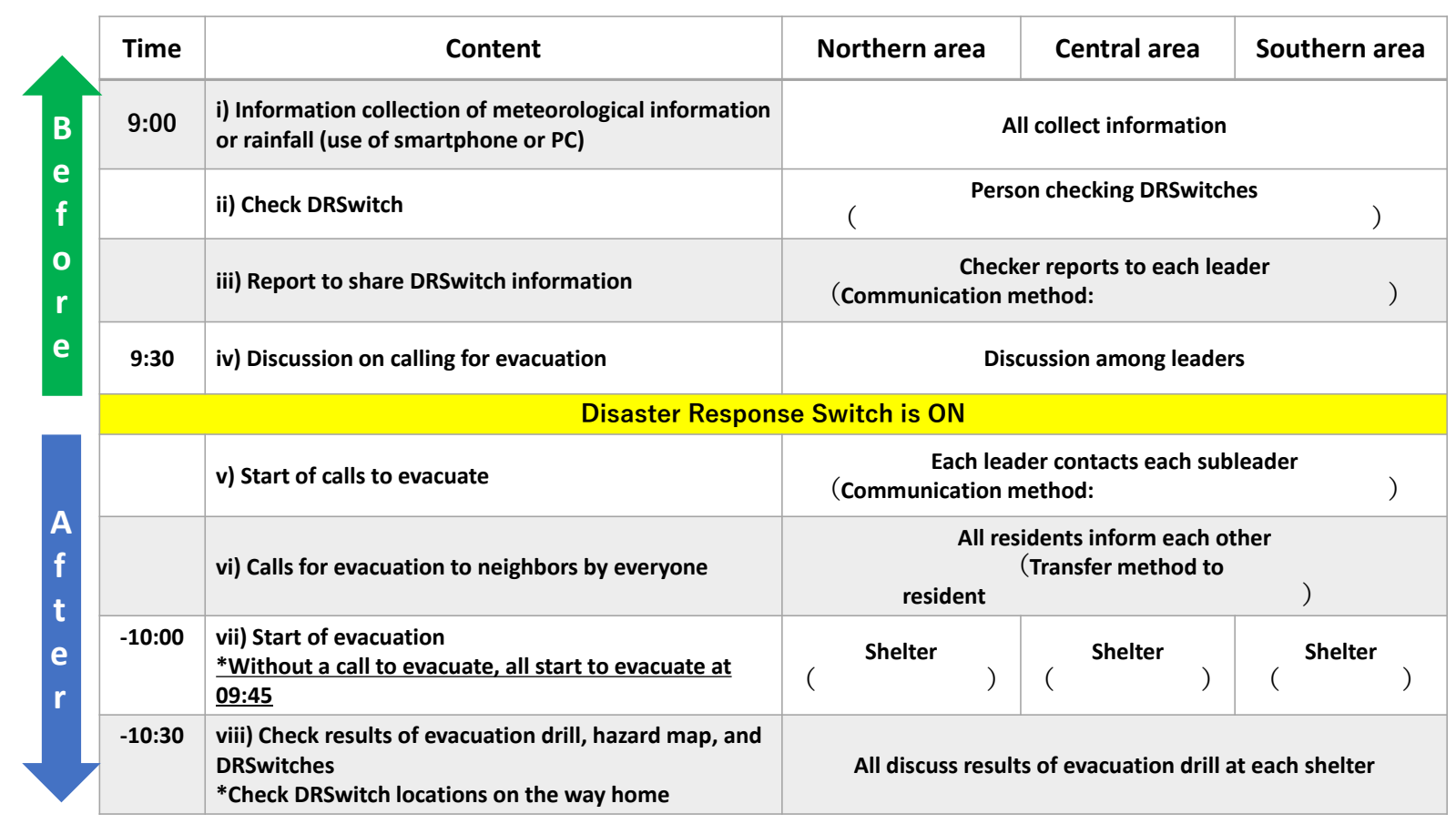

Figure 3. Flowchart of DRSwitch evacuation drill (WS3, WS4)

WS4: DRSwitch evacuation drill by general residents of the communities (9:00-11:00 September 1, 2019; northern area: 70 persons; central area: 95 persons; southern area: 93 persons)

The district has held an annual evacuation drill, but the method has been simple. The local government broadcasts an evacuation information test through the administrative radio system, and the residents of the communities gather at shelters. The number of participants was low, sometimes just a few dozen. Therefore, we planned an evacuation drill using the DRSwitches selected in WS2. First, the leaders in the community communicated with the checker of each DRSwitch to learn the local situation. Next, if any situations applied to a DRSwitch (meaning the DRSwitch was activated), the communities switched their behavior and consciousness from normal mode to disaster mode. The leaders began to call for evacuation using various methods, such as telephone or e-mail. Finally, the residents of the communities evacuated to shelters while calling for the evacuation of others located around their houses. After gathering at the shelters, they rechecked the DRSwitches and landslide risk for the areas around their homes.

WS5: Connection between local and public disaster risk information (18:00-20:00 October 25,$2019 ; 15$ persons)

In the period of this trial, some members of the committee attempted bosai (disaster prevention) recording, taking pictures of the situation of each DRSwitch when they noticed certain phenomena or dangerous situations. Some selected checkers tried this recording not by 
going to each spot when there was heavy rainfall but by observing from safe places such as from their home's windows, which would be done in a disaster, depending on the situation.

This bosai recording by the communities was conducted for DRSwitches on flood risk in Takenouchi et al. (2020). However, we clearly cannot judge the relationships between the rainfall situation and landslide risk; therefore, this bosai recording takes the role of uncovering local risks. Some members tried bosai recording after WS2. In WS5, they brought photos related to the DRSwitches and compared them with the public disaster risk information to better understand their DRSwitches.

WS6: Summary (18:00-19:30 February 25, 2020; 30 persons)

The committee discussed three points: i) good points, ii) issues, and iii) future plans. The constructed DRSwitches were regarded as somewhat subjective; therefore, the committee thought it necessary to make them more accurate and easier to understand using objective data. Thus, the committee discussed community observation systems using IoT devices (IoT-COS), such as soil water content or spring water levels, in a later trial (as IoT-COS is outside the scope of this study, the details are omitted from this paper).

These workshops were conducted as fieldwork, including questionnaire surveys, to confirm participants' opinions.

The next section assesses the results of the trial from three viewpoints: i) Results of DRSwitches for landslides and bosai recording, ii) Results of the DRSwitch evacuation drill, and iii) Communities' opinions on the DRSwitch trial. This includes an examination of the effects of, issues with, and community opinions of public participation in disaster risk information for uncertain landslide risks.

\section{RESULTS}

Here, we first confirm the constructed DRSwitches, view the results of the DRSwitch evacuation drill, and then finally confirm the results on the communities in this trial.

\subsection{Results of DRSwitches for landslides and bosai recording}

Figure 1 shows the results of the DRSwitches selected in WS1 and WS2. These DRSwitches have two characteristics. One is that some landslides can occur near residential areas. In these cases, the DRSwitches indicate the general precursory phenomena of landslides such as "Be careful of earthy smells or falling stones." The other is that some landslides can occur far from residential areas, such as around the tops of mountains. In these cases, the DRSwitches indicate 
the indirect phenomena of landslides that change with risk level in lower areas, such as "Be careful of muddy or unusual amounts of water discharged from the retaining wall" or "Mind the amount of water in the gully at the Nakamachi garbage collection location." In Takenouchi et al. (2020), most of the DRSwitches on flood risk clearly indicated changes in the observable values related to flooding, such as "when the water level reaches two-thirds of the height of the dike." In this trial, indirect evaluations were the main checkpoints, such as unusual situations, precursory phenomena, or the amount of water in a gully. Once a landslide occurs, certain options become impossible but evaluating the risk is very difficult. Therefore, we can consider DRSwitches for landslides likely to contain indirect information.

Northern group "switch on flow in small gully near xxx's house"

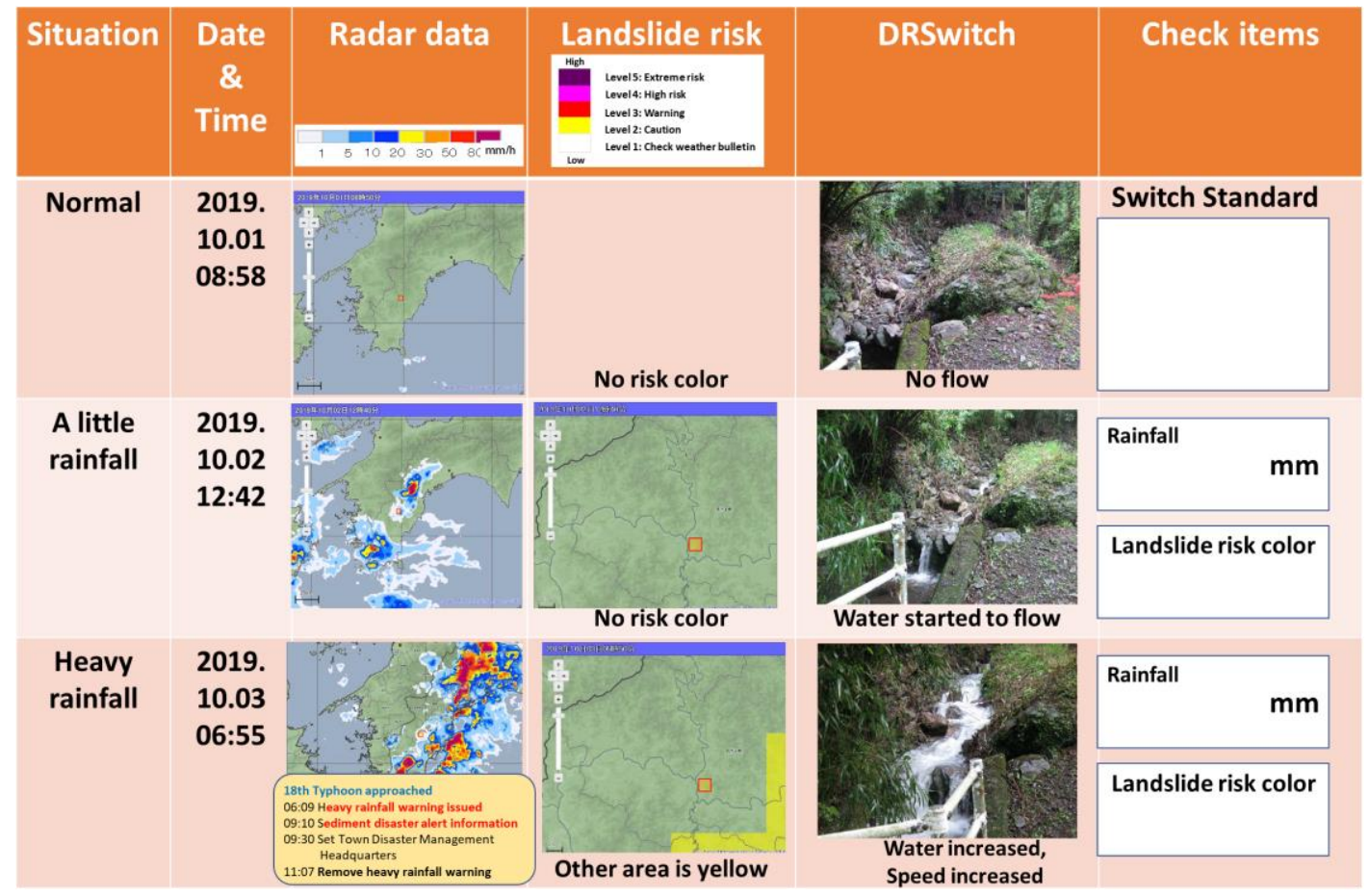

Figure 4. Example of checking bosai recordings (WS5)

After WS2, some members attempted bosai recording to record the situations of the selected DRSwitches. Figure 4 shows an example of a comparison between bosai recording and public disaster risk information in WS5. Here, communities can check the relationships between the DRSwitches and the meteorological situations, such as the amount of rainfall, based on the bosai recordings. Thus, the communities share a common recognition of the DRSwitches in their communities. Although the DRSwitches tend to be subjective and indirect, the situations can be considered more fully using the DRSwitches with public disaster risk information through bosai recordings. 


\subsection{Results of DRSwitch evacuation drill}

This section presents the results of the DRSwitch evacuation drill in WS4.

The actual methods for activities after DRSwitches can be considered adjustments in each case. In this trial, the communities had an evacuation drill using the constructed DRSwitches. We checked the effects or issues with this evacuation drill. As Figure 3 shows, the communities checked each DRSwitch and followed the action of calling to neighbors for evacuation. Figure 5 shows the timing of the call to evacuate in this drill. The results show that $74 \%$ of the participants heard the call to evacuate within 10 minutes, and almost all participants heard the call to evacuate within 20 minutes. This result confirms that the call to evacuate in neighborhoods with a DRSwitch can be effective for evacuation in a mountainous area. The method for the call to evacuate was oral in $65 \%$ of cases and by telephone in $24 \%$. Although $11 \%$ of the community residents could not hear the calls for evacuation, they evacuated under their own judgment because they knew that the evacuation drill started from 9:00 a.m. The average number of persons called by a single participant was 2.9 ; most people were called by neighbors or community leaders. This was the first trial with calls to evacuate in this community, and some dependency on leaders was found; therefore, the promotion of calls to evacuate neighborhoods was an issue.

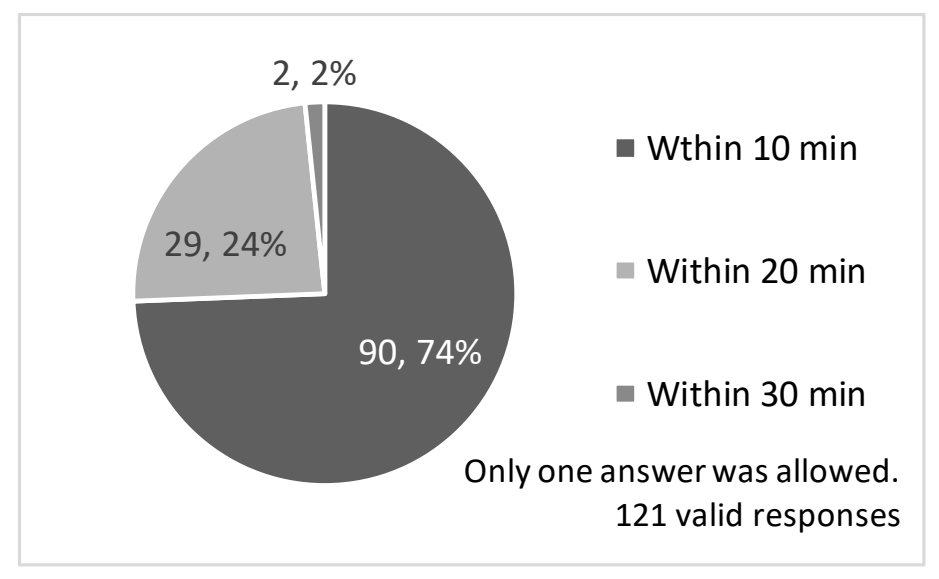

Figure 5. Timing of received calls to evacuate during the DRSwitch evacuation drill (WS4)

Figure 6 shows the possibility of calls to evacuate during actual disasters. As $87 \%$ of the participants answered "Possible" or "Somewhat possible," to the question of evacuation, most communities expressed no hesitance to call for an evacuation. However, $7 \%$ answered "Impossible," indicating that the surrounding communities need to support them. 


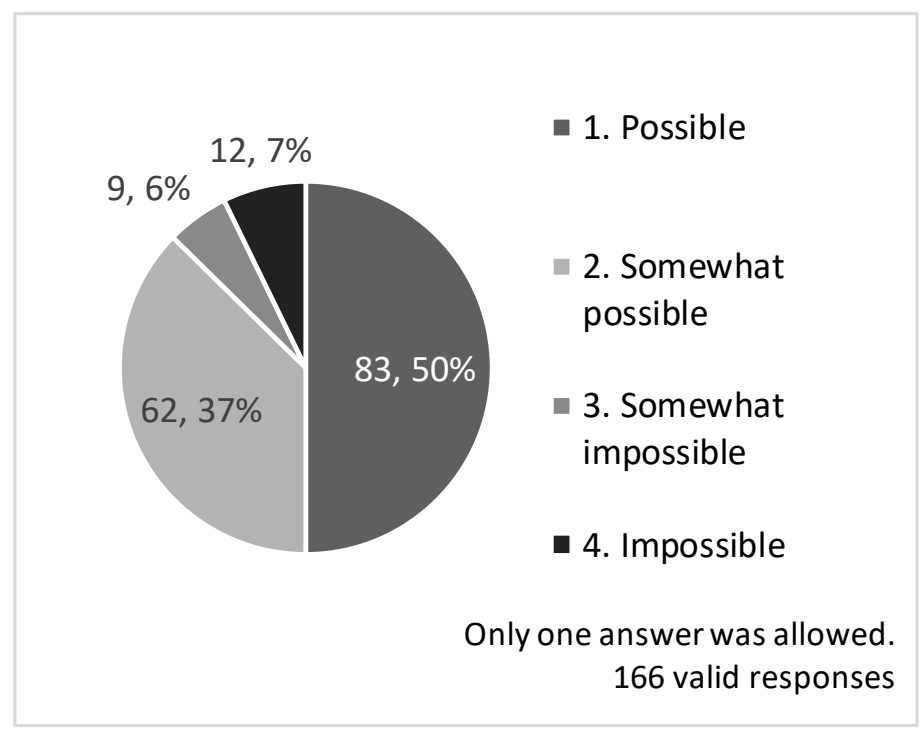

Figure 6. Possibility of calls to evacuate in a real disaster situation (WS4)

Figure 7 shows the advantages of this evacuation drill compared to a conventional one. The most advantageous point was that participants stated that the drill was "more relevant to me." This may be because we used DRSwitches made by the communities and because the communities themselves called for the evacuation. Moreover, 45 persons tried "with more seriousness," indicating that they approached the evacuation drill with more practical intent.

The constructed DRSwitches worked effectively as the origin of this evacuation drill.

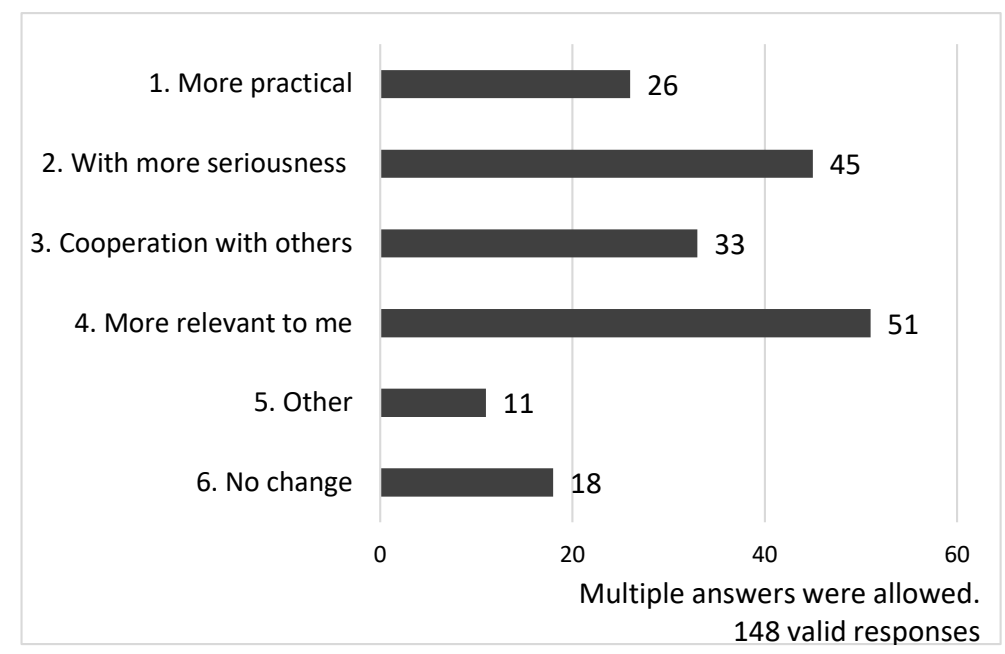

Figure 7. Advantages of the DRSwitch evacuation drill (WS4) 


\subsection{Communities' opinions on DRSwitch trial}

This section examines communities' opinions about the DRSwitch trial based on the results of questionnaire surveys from some of the workshops.

WS1 assessed seven activities for local disaster prevention (A-G) before the trial. Figure 8 shows the resulting activities that the communities considered important and notes which were actually conducted. A low rate of actual practice was found for " $\mathrm{C}$. We should decide which responses to take," (30\%) "D. We should decide when to respond," (29\%) and "F. We should prepare to communicate with family members and neighbors" (31\%). The DRSwitch especially focuses on item $\mathrm{D}$, but the resident did not consider specific actions as in item $\mathrm{C}$ or item $\mathrm{F}$.

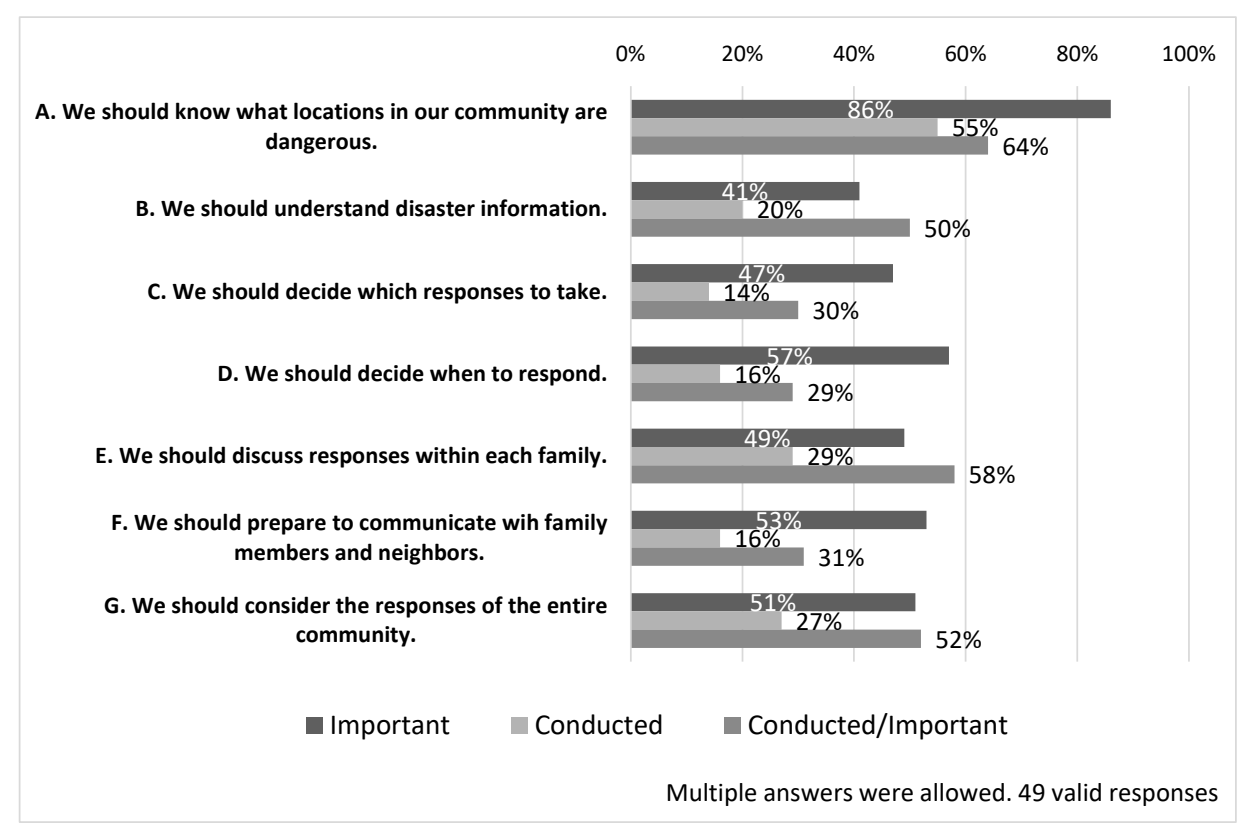

Figure 8. Disaster prevention activities for meteorological disasters in the Taisho District (WS1)

The questionnaire in WS3 checked whether participants judged the evaluation of evacuation from landslides to be difficult. Overall, 83\% answered "Difficult," and all others answered "Somewhat difficult." Figure 9 shows the rank order of the reasons for this difficulty. "I don't know when a landslide happens," and "I don't know how dangerous the current situation is" were the primary reasons. These reasons are derived from the locality and uncertainty of landslides. Discussion of when communities should take action regarding landslides was insufficient, and the communities did not have a method to judge the risk. 


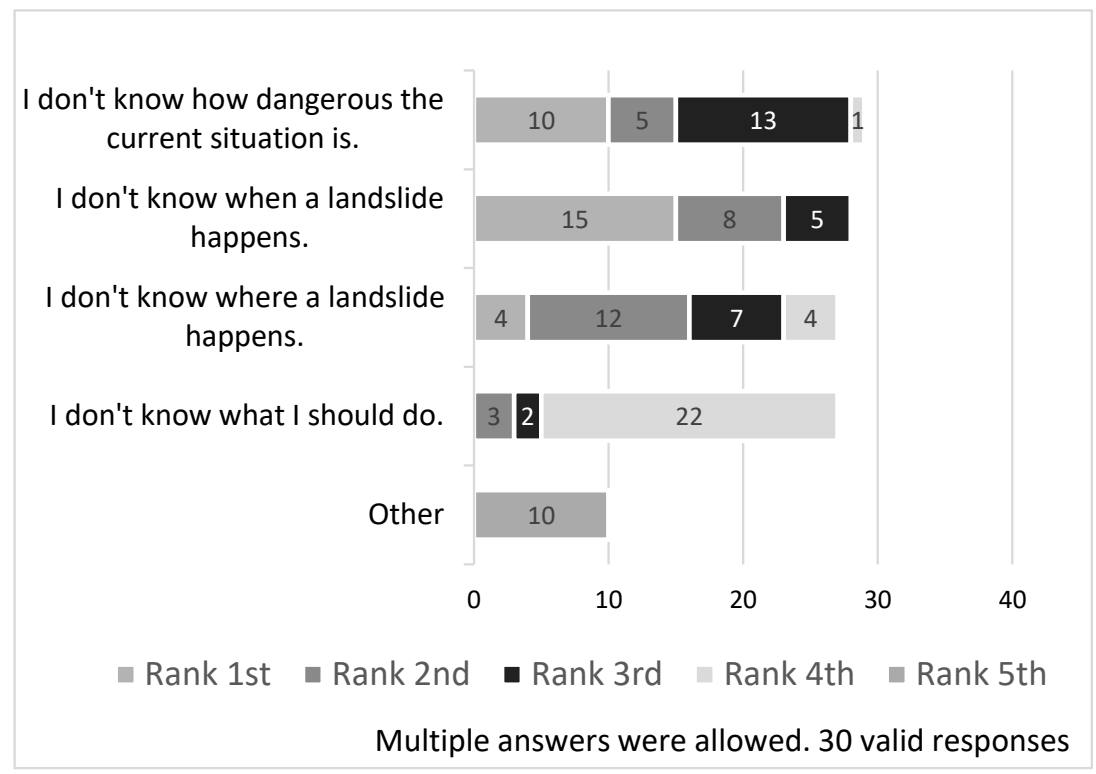

Figure 9. Rank order of reasons for difficulty in judging evacuation from landslides (WS3)

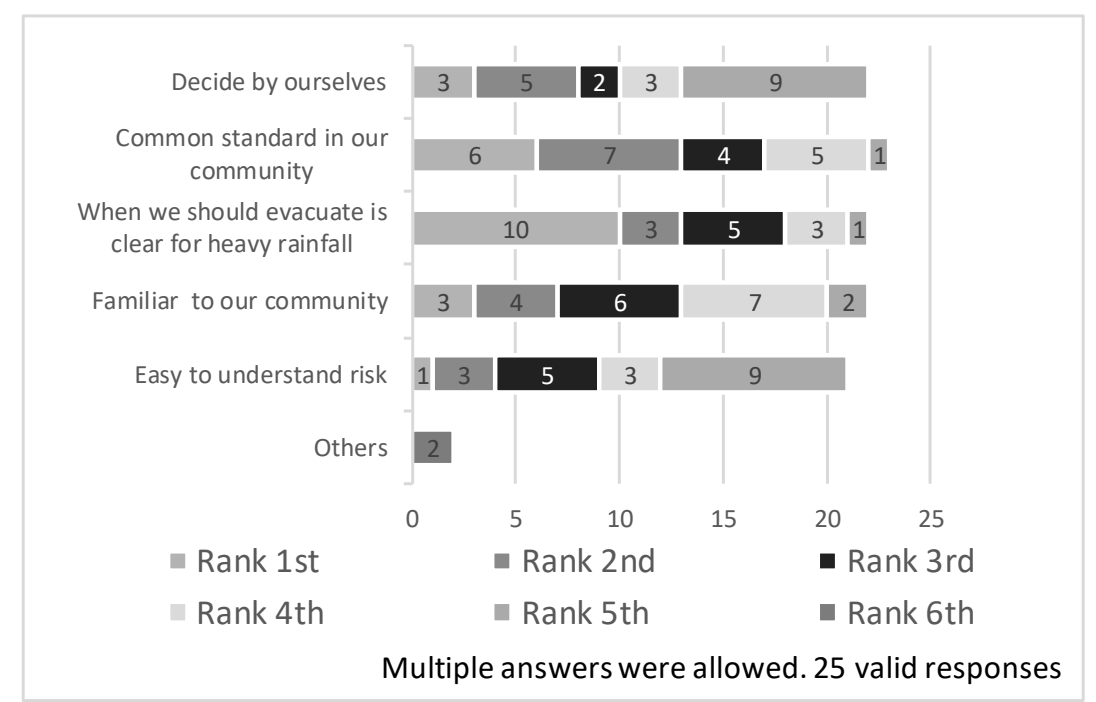

Figure 10. Rank order of reasons why DRSwitches can lead to evacuation (WS2)

In a landslide situation, how could the DRSwitch work?

WS2 checked whether the constructed DRSwitches were useful for the timing of the evacuation. Given a statement asserting DRSwitch usefulness, $48 \%$ of participants answered, "I agree totally," and the remaining 52\% answered, "I agree somewhat." Figure 10 displays the rank order of the reasons for their agreement. "When we should evacuate is clear for heavy rainfall" was the most frequently cited reason, indicating that the DRSwitches are a solution to the problem of evacuating from a landslide. The second most frequent reason was that DRSwitches could become a "common standard in our community"; therefore, the communities may regard evacuation as an action for the entire community and may favor 
cooperative evacuation in the community over individual action. Other general residents of the communities (158 participants in WS4) answered similarly positively: 66\% answered, "I agree totally," and 32\% answered, "I agree somewhat" to the question "Do you think the DRSwitches can be used for the timing of evacuation?"

Next, we investigated the opinions about public participation in disaster risk information by communities, as in the case of DRSwitches, to assess what communities think about not depending on the local government and, instead, joining in to consider evacuation timing based on local disaster risk information. Figure 11 shows the results of the questionnaire from WS4. Before this trial, the communities only received evacuation information from the local government, and often they did not take evacuation actions. However, the DRSwitch trial changed this concept. Figure 11 shows that $91 \%$ of participants answered, "We need to discuss evacuation timing together." Figure 12 shows points considered important for public participation in evacuation judgments. A high percentage of respondents noted the following: "It produces an opportunity to consider evacuation in the community" and "It increases evacuation awareness in the community", both of which likely derive from effects of the public participation. In addition, about a third of the participants selected "We can prepare for local situations not known to local government" and "We can identify points that we don't understand enough," indicating that the communities consider cooperation between themselves and the local government as important.

While it is difficult to judge the need to evacuate in response to landslide risk, public participation using DRSwitches gave communities an answer to the question "When should we evacuate?" and promoted an understanding of the importance of public participation in disaster risk information.

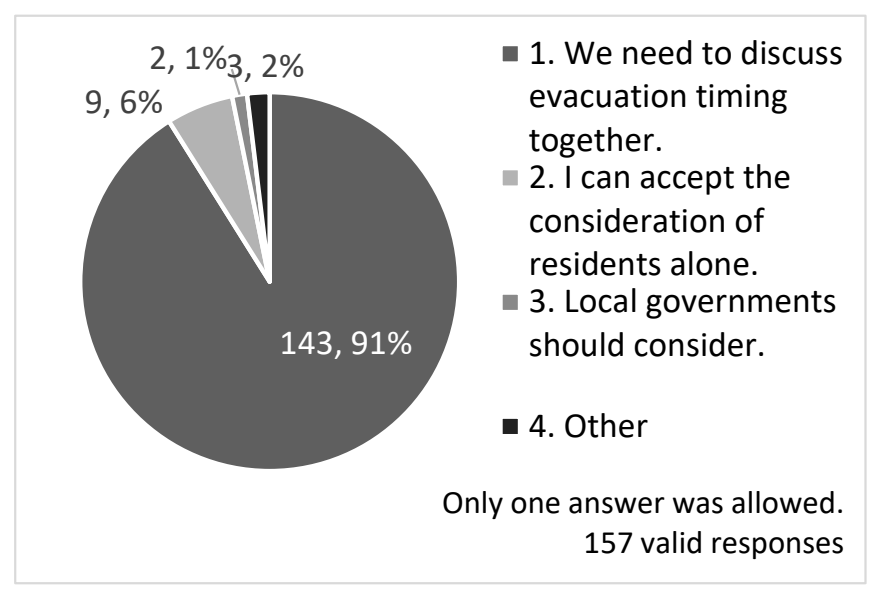

Figure 11. Opinions on public participation in evacuation judgments (WS4) 


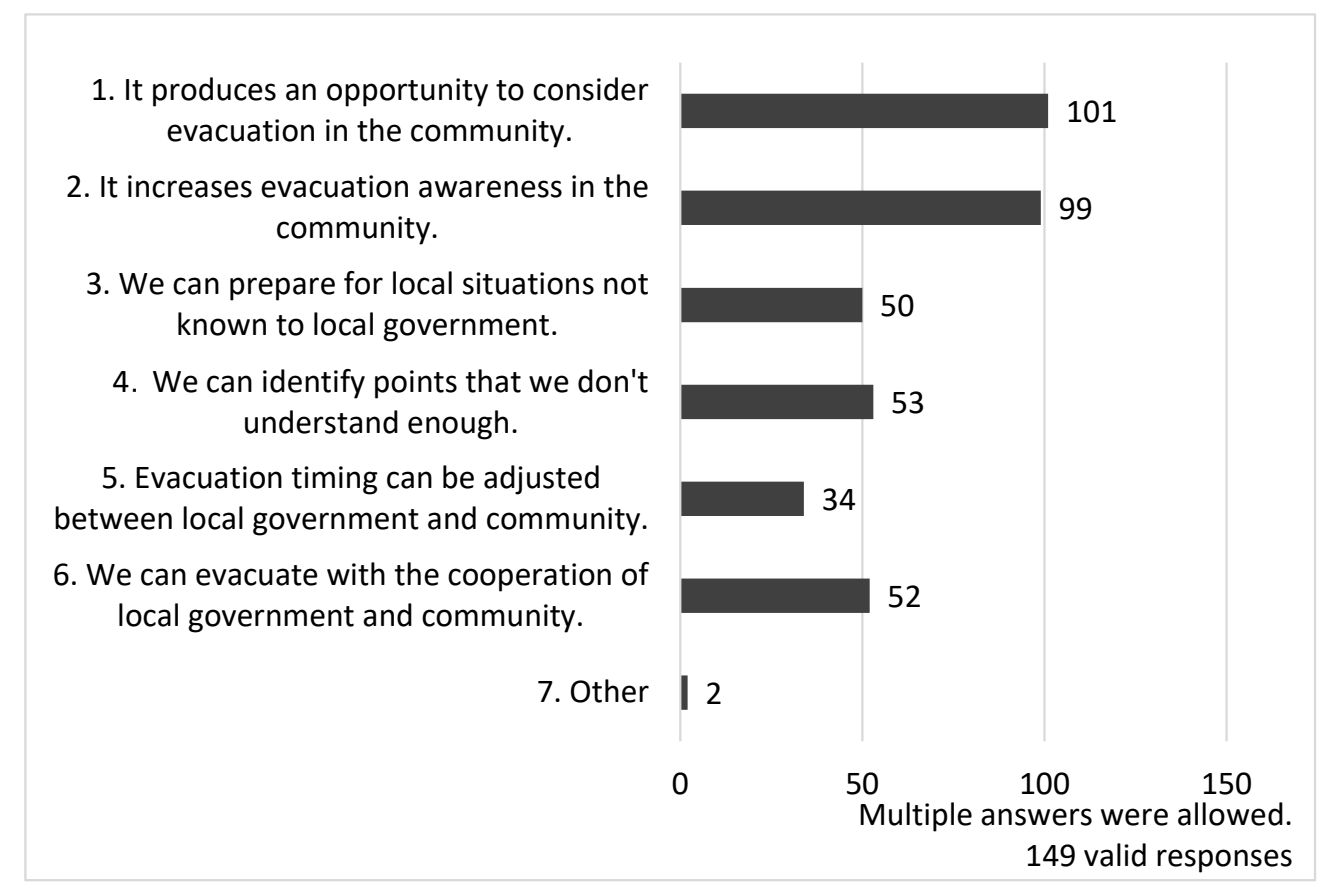

Figure 12. Reasons for the importance of public participation in evacuation judgments (WS4)

At the last workshop, the WS6 committee discussed the following: i) good points, ii) issues, and iii) future plans. Table 1 summarizes their resulting opinions, and Figure 13 shows their opinions on the following: i) the whole trial, ii) the constructed DRSwitches, iii) the Evacuation drill using DRSwitches, iv) bosai recording, and v) the continuous desire to keep the DRSwitches.

Regarding good points, the committee members showed highly improved disaster awareness. In addition, some members emphasized that the constructed DRSwitches are concrete and effective for real disasters. Additionally, this trial created better communication among the participating communities. However, not all aspects were positive. Participants regarded the operation system as an issue; communications sometimes took a long time among leaders, DRSwitch checkers, and the persons designated to call for evacuation in an evacuation drill. This means that, when considering disaster situations, some members thought this system should be changed so that the checkers judge and inform the communities. They discussed improvements, including a contact list, in WS6. In addition, the members discussed the necessity of understanding the DRSwitches and the greater participation of other communities. As future plans, continuity and more trials were common topics. The members considered DRSwitches to be one disaster prevention culture in their community.

Figure 13 displays the participants' opinions of the DRSwitch trial. Most of the members answered positively about each point. 
Table 1. Opinions of summary on DRSwitch trial (WS6)

\begin{tabular}{|c|c|}
\hline i) good points & $\begin{array}{l}\text { - } \text { Improved disaster awareness. } \\
\text { - Created more concrete actions in the community. } \\
\text { - } \quad \text { Constructed DRSwitches that can work efficiently in real disasters. } \\
\text { - } \quad \text { Communities communicate better than before. } \\
\text { - Checked risky areas and evacuation routes. }\end{array}$ \\
\hline ii) issues & $\begin{array}{l}\text { - Leaders must improve the operation system. } \\
\text { - Other residents need to understand the DRSwitches and join much } \\
\text { more. } \\
\text { - DRSwitch standards need to be more accurate. }\end{array}$ \\
\hline iii) future plan & $\begin{array}{l}\text { - } \\
\text { - } \quad \text { Continue this trial and more drills. } \\
\text { - Improve communities' disaster awareness. } \\
\text { - Improve the DRSwitch evacuation drill. }\end{array}$ \\
\hline
\end{tabular}

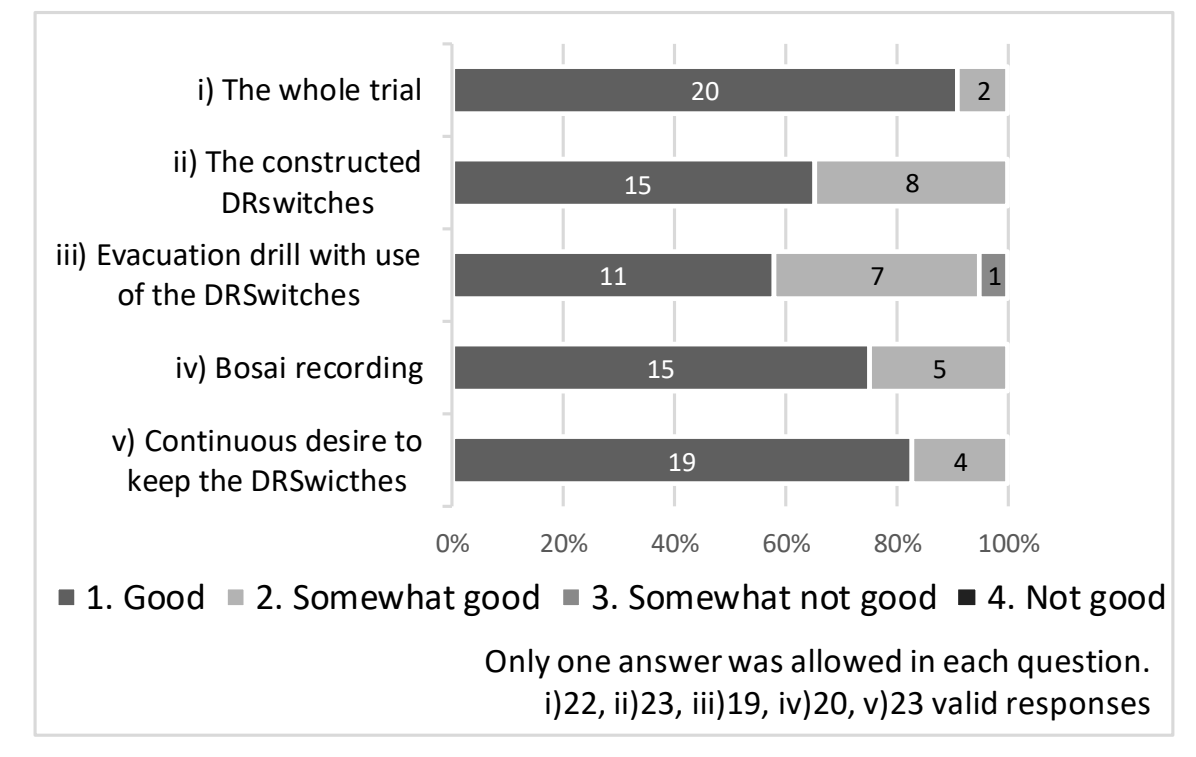

Figure 13. Overall opinions and those for each activity in this trial (WS6)

\section{DISCUSSION}

Landslides occur locally and are not easily predicted. However, the trial of DRSwitches for landslides created an opportunity for communities to consider the timing of evacuation using community participation in disaster risk information. In addition, the communities could connect their DRSwitches and public disaster risk information using bosai recordings. 
From the previous section's results, we consider the ideal state of public participation in disaster risk information for landslides.

\subsection{Construction of relationships between the local situation and objective information}

This trial of DRSwitches for landslide risk identified some local disaster risk information to reference evacuation timing; however, the trial included slightly subjective content that was different from that applicable to flood risk. Therefore, there was some uncertainty regarding the risk information for disasters. Some communities tried bosai recording, which could link uncertain information with objective and quantifiable public disaster risk information. In other cases, such as debris flow, professional volunteers in a Taiwanese community, and weather reporters in Weathernews Inc., systems have taken steps to evaluate local disaster risk. The method in this study led to the construction of another system. First, the communities gained an understanding of local risk information in the community, and subsequently, they evaluated these relationships with quantifiable public disaster risk information.

In general, observation of rainfall amounts is a representative example of public participation in disaster risk information; however, as observation systems have increased in society, it has become more difficult for lay members of the public to participate in these systems. This tendency can lead to a weak relationship between disaster risk information and communities and an over-dependence on public disaster risk information from professionals. In fact, the latter case applies to most Japanese communities, including the Taisho District. DRSwitches can change these relationships. DRSwitches promote public participation by considering local disaster risk information. Participants rebuild the relationship between communities and public disaster risk information by recording local situations. Against this background of weakening public independence supplemented with more additional information, bosai recording can increase the independence of risk-assessment information and connect subjective local disaster risk information and objective public disaster risk information.

Separately from communities, some technological developments can determine local landslide risk information based on observations by inexpensive IoT devices (Ueyama et al. 2018). As some communities in the Taisho District expressed that they wanted to clarify the conditions of the local mountains, we discussed the possibility of installing some of these devices during WS6. Caution is important when constructing such a local observation system; even if we can easily obtain objective and quantifiable local risk information on landslides, the relationship between disaster risk information and communities will not change without a system of public participation. The most local and accurate information does not necessarily equate to a change in the position of information in the social system but rather equates to differences in the observed items or accuracy. Similarly, such an approach cannot promote the change in information awareness we found in this trial. Public participation using DRSwitches provides an approach to addressing some issues that an improvement in locality or accuracy cannot resolve. 


\subsection{Desire to participate in disaster risk information}

Some questionnaire survey results showed the effect of the public participation method. DRSwitches can resolve the difficulty in making evacuation judgments, which derive from the highly local and uncertain nature of landslide risk. Generally, we focus on the content or accuracy of information when we discuss the improvement of disaster risk information. However, as we cannot forecast landslide occurrence with $100 \%$ accuracy, some uncertainty remains.

In this discussion, the DRSwitch moves the focus from the content or accuracy of disaster risk information to a community system of disaster evacuation ("How do communities cooperatively evacuate?") through community participation in disaster risk information. The results here showed that residents could accept uncertainty in disaster risk information, or, if they have no awareness of disaster risk information, that they can consider their own evacuation timing. This can be seen in that most communities thought that DRSwitches could be used for evacuation timing.

As Figure 10 shows, positive opinions on public participation in disaster risk information are important. Figure 14 shows a conceptual model of communities' disaster responses based on disaster risk information. The Figure 14a is for a conventional approach in which the local government issues evacuation information, and communities receive it and consider disaster responses. This is quite typical today. However, the low rate of evacuation in Japan shows that this style cannot work sufficiently there. Effectiveness depends on the various aspects of nations, communities, cultures, and disaster characteristics. Public participation can change this conceptual model into the Figure 14b. If evacuation information on landslide risk is issued by local governments based on scientific standards, the communities sometimes do not feel that the information is realistic and often wonder whether they actually need to evacuate. The DRSwitch approach departs from this conventional approach; in this approach, communities not only receive disaster risk information but also evaluate landslide risk for themselves and take actions based on the DRSwitches. Their roles expand to include checking local risks by adding local items to the evacuation-judgment process. The DRSwitch changes communities' perspectives from considering evacuation (which may not produce action) to judging them (which can lead to action). The results in Figure 13 support this type of approach.

DRSwitches can create an opportunity to discuss action standards or risk information through the lens of cooperation between local government and communities. Such cooperative construction is important for promoting landslide evacuation. 

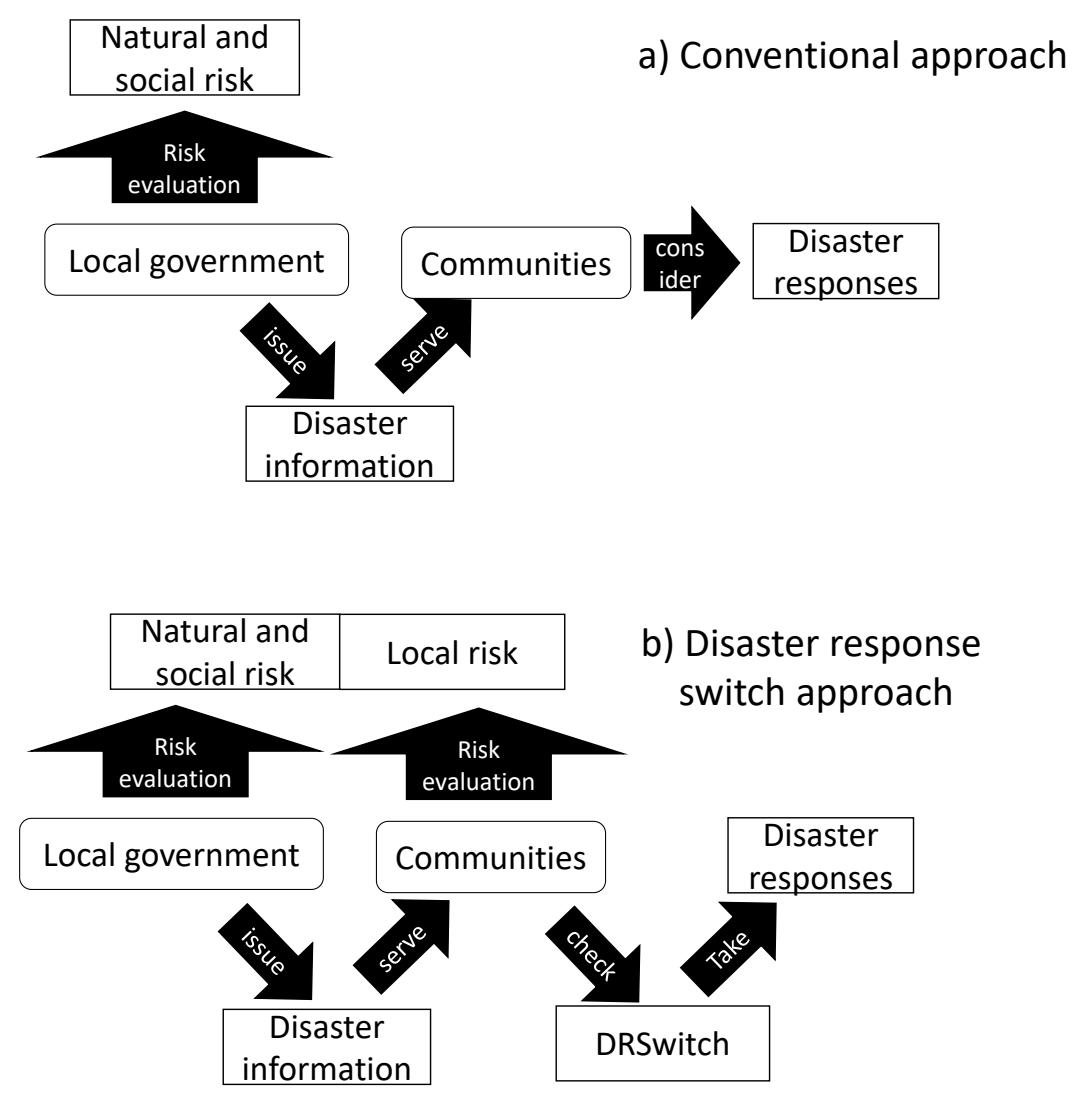

Figure 14. Conceptual model of communities' disaster responses based on disaster risk information a) conventional approach; b) DRSwitch approach

\section{SUMMARY}

Through practical research in a mountainous area of Japan, this study verified the effects and issues of public participation via DRSwitches with respect to highly local and uncertain landslide risk.

Communities participated in this trial and constructed DRSwitches based on local disaster risk information. Thus, the communities accepted the uncertainty in disaster risk information on landslide risk and simultaneously connected their subjective local disaster risk information to objective public disaster risk information through bosai recording. This trial thus resolved the over-dependency on local government information and allowed the communities to reconstruct their concepts of evacuation. Consequently, the DRSwitch promoted an independent attitude toward evacuation from landslides.

This trial was conducted in a mountainous area, and therefore, it was easy for the community to accept the concept of common evacuation. However, some locations, such as urban areas with landslide risk, make it more difficult to forge cooperation within communities. If community communication is difficult, some communities, such as representatives of voluntary disaster prevention organizations, should first attempt DRSwitch construction. It is 
not known whether this will lead to the same effects as seen in this study; additional verification is required for urban areas.

The issue of technology is also a challenge for the future. Smartphones, AI, Big Data, and technological developments have become increasingly widespread in social systems, causing community systems for local disaster prevention to change. As the methods of public participation in disaster risk information continue to change, we must attempt additional and ongoing research on the proper methods to adjust to these technological changes.

\section{ACKNOWLEDGEMENT}

The researcher would like to thank the communities in the Taisho District and the officers in the Shimanto-cho local government of Kochi, Japan. This study was partially supported by JSPS KAKENHI, Grant-in-Aid for Challenging Research Pioneering, Grant Number JP 20K2033 (PI: Katsuya Yamori).

\section{REFERENCES}

Asakura, Y., Hangyo, M., and Komachi, M. (2016) Disaster Analysis using UserGenerated Weather Report, Proceedings of the 2nd Workshop on Noisy User-generated Text, pp.24-32.

Atkinson, G. M., and Wald, D. J. (2007) “Did You Feel It?” Intensity Data: A Surprisingly Good Measure of Earthquake Ground Motion, Seismological Research Letters, Vol. 78, No. 3, pp.362-368.

Aulov, O., and Halem, M. (2012) Human Sensor Networks for Improved Modeling of Natural Disasters, Proceedings of the IEEE, Vol.100, No.10, pp.2812-2823.

Baudoin, M. A., Shepard, S. H., Fernando, N., Sitati, A., and Zommers, Z. (2016) "From Top-Down to "Community-Centric" Approaches to Early Warning Systems: Exploring Pathways to Improve Disaster Risk Reduction Through Community Participation," International, Journal of Disaster Risk Science, Vol.7, No.2, pp.163-174.

Catherine C. A., Primo, C. C., and Tabios III., D. G. Q. (2012) Community based monitoring for flood early warning system: An example in central Bicol River basin, Philippines, Disaster Prevention and Management, Vol.21, No.1, pp.85-96.

Chen, C. Y., and Fujita, M. (2013) Evacuation Decision-Making Factors for Local Governments and Inhabitants in Debris-Flow Potential Areas in Taiwan, International Journal of Erosion Control Engineering, Vol.6, No.2, pp.37-46.

Chen, S. C., and Huang, B. T. (2010) Non-structural mitigation programs for sedimentrelated disasters after the Chichi Earthquake in Taiwan, Journal of Mountain Science, Vol.7, No.3, pp.291-300. 
Chen, S. C., and Wu, C. Y. (2014) Debris Flow Disaster Prevention and Mitigation of Non-Structural Strategies in Taiwan, Journal of Mountain Science, Vol.11, No.2 pp.308-322.

Chiba, M., Katayama, Y., Miki, Y., and Takanashi, K. (2008) Information sharing concerning warning of, and evacuation plans from, sediment-related disasters, Journal of the Japan Society of Erosion Control Engineering, Vol.60, No.6, pp.33-37 (in Japanese).

Cremen, G., Gupta, A., and Baker, J. (2017) Evaluation of ground motion intensities from induced earthquakes using "Did You Feel It?", 16th World Conference on Earthquake, Paper No.3365.

Gautam, D. K., and Phaiju, A. G. (2013) Community Based Approach to Flood Early Warning in West Rapti River Basin of Nepal, Journal of Integrated Disaster Risk Management, Vol.3, No.1, pp.155-169.

Hoeppe P. (2015) Trends in weather related disasters - Consequences for insurers and society, Weather and Climate Extremes, Vol.11, pp.70-79.

Huang, B., Zheng, W., Yu, Z., and Liu, G. (2015) A successful case of emergency landslide response - the Sept. 2, 2014, Shanshucao landslide, Three Gorges Reservoir, China, Geoenvironmental Disasters, Vol.2, No.18, pp.1-9.

Irasawa, M., and Endo, Y. (2010) An opinion poll administered to Kamaishi City residents about sediment disaster generated by rainfall in July 2002, Bulletin of the Iwate University, Vol. 41, pp. 259-272 (in Japanese).

Japan Fire and Disaster Management (2016) Sharing information with tablet devices, cases for improvement and strengthening of volunteer fire groups, Japan.

https://www.fdma.go.jp/relocation/syobodan/torikumi-jirei/pdf/28_hyogo.pdf (in Japanese)

Japan Meteorological Agency (2020) Meteorological disaster cases (1989-2020). https://www.data.jma.go.jp/obd/stats/data/bosai/report/index_1989.html

Kikui, T., and Sano, H. (2008) Consciousness of inhabitants and the correspondence to warning-evacuation in the sediment-related disaster, Journal of the Japan Society of Erosion Control Engineering, Vol.60, No.6, pp.48-51 (in Japanese).

Marchezini, V., Trajber, R., Olivato, D., Muñoz, V. A., Pereira, F. O., and Luz, A. E. O. (2017) Participatory Early Warning Systems: Youth, Citizen Science, and Intergenerational Dialogues on Disaster Risk Reduction in Brazil, International Journal of Disaster Risk Science, Vol. 8, No. 4, pp. 390-401.

Ministry of Land, Infrastructure, Transport and Tourism (2019) Designating situations of landslide disaster warning areas in Japan.

http://www.mlit.go.jp/river/sabo/sinpoupdf/jyoukyou-190228.pdf (in Jpanese)

Okada, K., Makihara, Y., Shimpo, A., Nagata, K., Kunitsugu, M., and Saito, K. (2001) Soil Water Index, Tenki, Vol.48, No.5, pp. 349-356 (in Japanese). 
Okamoto, A., Tomita, Y., Mizuno, M., Hayashi, S., Nishimoto, H., Ishii, Y., and Chiba, S. (2012) The data analysis regarding the warning and evacuation information against sedimentrelated disaster, Natural Institute for Land and Infrastructure Management, No.682 (in Japanese).

Oi, H., Omachi, T., and Ueda, S. (2016) 4.4 Development of rain gauge and water-level gauge for community disaster prevention, Landslide disasters and disaster reduction education, pp.70-73, Asakura Press (in Japanese).

Japan Erosion and Sediment Control Department (2009) Plan of guideline for support of education on landslide disaster prevention, http://www.sabopc.or.jp/images/library/images/guidebook.pdf (in Japanese)

Segoni, S., Piciullo, L., and Gariano, S. L. (2018) A review of the recent literature on rainfall thresholds for landslide occurrence, Landslides, Vol.15, pp.1483-1501.

Smith, P.J., Brown, S., and Dugar, S. (2017) Community-based early warning systems for flood risk mitigation in Nepal, Natural Hazards and Earth Sciences, Vol.17, No.3, pp.423437.

Takahashi, K., Y. Kono, S., and Nakamura (2005) Study on behaviors and consciousness of residents of Atsumari district during debris flow in Atsumari district of Minamata city on July 20, Journal of Japan society for natural disaster science, Vol.24, No.1, pp.38-48 (in Japanese).

Takenouchi, K., Yamori, K., Chiba, R., Matsuda, T., and Izutani E. (2020) Construction of Disaster Response Switch in a Community through a Trial with Kawamo Community in Takarazuka City in Japan, Disaster Information studies, Vol.18, No.1, printing (in Japanese).

Tamura K. (2016) A Study of Countermeasures for Disaster Reduction in Municipalities: Risk Communication between Local Government Employees and Citizens on Torrential Rain Case, The bulletin of the Graduate School of Policy Science, Ryukoku University, No.4, pp.71-91. (in Japanese)

United Nations (2015) Sendai Framework for Disaster Risk Reduction 2015-2030, http://www.unisdr.org/we/coordinate/sendai-framework

Ushiyama M. (2015) Causal analysis of human damages by strong rainfalls from 2004 to 2014, Tohoku research for natural disaster science, No.51, pp.1-6 (in Japanese).

Wald D. J., Quitoriano, V., Worden, B., Hopper, M., and Dewey, J. W. (2011) USGS “Did You Feel It?” Internet-based macroseismic intensity maps, Analysis of geophysics, Vol.54, No.6, pp.688-707.

Weathernews Inc. (2016) Disaster reduction and mitigation by participation and share in self- and mutual-helps, Japan. http://ictfss.nict.go.jp/ictfss-2016/1_unozawa.pdf (in Japanese) 